\title{
Alfabetização Matemática entrelaçada à Literatura Infantil: um estudo da percepção de professores alfabetizadores
}

\section{Mathematical Literacy interlaced with Children's Literature: a study on the perception held by literacy teachers}

\author{
Karin Ritter Jelinek, ${ }^{1}$ \\ Márcia Viviane dos Santos Adam²
}

\begin{abstract}
Resumo: É notável na atualidade a dificuldade dos estudantes da Educação Básica em compreender os conceitos da Matemática, pois muitas vezes não construíram noções matemáticas fundamentais ao Ciclo de Alfabetização. Sabe-se, também, da importância da utilização de estratégias de ensino diversificadas para que o aluno construa nessa etapa os conceitos matemáticos que são tidos como base para o seu sucesso nos demais níveis de ensino. Entendemos que uma alternativa que se encaminha a esse encontro é a Alfabetização Matemática entrelaçada à Literatura Infantil. Nos últimos anos o Ministério da Educação enviou para as escolas acervos de obras literárias que trazem ideias que podem ser exploradas em diversas áreas do conhecimento, inclusive da Matemática. Desse modo, desenvolveu-se uma pesquisa qualitativa, com aspectos quantitativos, com professores alfabetizadores, com o objetivo de verificar se eles consideram possível a utilização de algumas histórias infantis que compõem tais acervos para introduzir ou construir conceitos matemáticos.
\end{abstract}

Palavras-chave: Literatura infantil; noções matemáticas; Alfabetização Matemática.

Abstract: It is noteworthy how primary and secondary students presently struggle to understand the concepts of Mathematics, as oftentimes they were unable to build mathematical notions that are fundamental to the literacy cycle. Another known fact is the importance of using diversified teaching strategies to allow students to build, during those years, the mathematical concepts that are held as the basis for their success in other educational stages. We understand that one alternative that is in line with this notion consists of interlacing mathematical literacy and children's literature together. Over the past few years, Brazil's Ministry of Education has been sending schools collections of literary works that bring in ideas which can be explored in various fields of knowledge, Mathematics included. Therefore, a qualitative research study with quantitative aspects was conducted with literacy teachers to find whether they think it is possible to use some of the stories for children found in such collections to introduce or build mathematical concepts.

\footnotetext{
${ }^{1}$ Doutorado em Educação pela Universidade Federal do Rio Grande do Sul (2013). Professora Adjunta na Universidade Federal do Rio Grande - FURG - Rio Grande do Sul - RS -Brasil - karinjelinek@ @ furg.br

${ }^{2}$ Mestranda pelo Programa de Pós-Graduação em Ensino de Ciências Exatas (FURG). Professora da Rede Pública de Ensino nos municípios de Glorinha e Gravataí (RS). Rio Grande do Sul - RS -Brasil vivianeadam@gmail.com
}

Tangram - Revista de Educação Matemática, Dourados - MS - v.3 n.1, pp. 02-17 (2020) 


\section{Alfabetização Matemática entrelaçada à Literatura Infantil: um estudo da percepção de professores alfabetizadores}

Keywords: Children's literature; mathematical notions; mathematical literacy.

\section{Considerações iniciais}

Uma das preocupações dentre os professores de Matemática da Educação Básica, se refere às dificuldades encontradas pelos alunos na compreensão dos conceitos trabalhados nesse componente curricular no decorrer dos anos finais do Ensino Fundamental e no Ensino Médio. Muitas vezes essas dificuldades originam-se no desconhecimento por parte dos alunos das noções matemáticas que espera-se que sejam desenvolvidas nos anos iniciais do Ensino Fundamental, especialmente no Ciclo de Alfabetização.

Entretanto, é importante ressaltar que há uma grande preocupação por parte dos professores que atuam nos anos iniciais do Ensino Fundamental - bem como, uma cobrança sobre tais professores por parte de algumas famílias -, que os estudantes consigam se alfabetizar linguísticamente, protelando a um segundo plano a abordagem dos conceitos necessários à Alfabetização Matemática. Percebe-se, ainda, que alguns docentes exploram apenas dos conceitos próprios da unidade temática dos Números, deixando de abordar as habilidades das demais áreas do conhecimento matemático propostas pela $\mathrm{BNCC}^{3}$ (BRASIL, 2018), resultando no desenvolvimento deficiente no campo da Alfabetização Matemática.

Desse modo, entende-se que há a necessidade de propor diferentes estratégias de ensino para introduzir os conceitos das diferentes unidades temáticas da Matemática, propiciando a sua construção ainda no Ciclo de Alfabetização. Entendemos que este ciclo deve ter por objetivo maior, não apenas a construção dos conceitos, mas sim o desenvolvimento das noções atreladas a estes conceitos. Ou seja, estendemos que no Ciclo da Alfabetização os professores não devam estar preocupados com a formalização dos conceitos ou dos algoritmos, mas sim, que possam explorar todas as ideias e noções atreladas a eles, preparando os estudantes para as formalizações futuras.

Uma das possíveis estratégias na qual acreditamos ser interessante investir é a utilização de histórias infantis aliadas ao ensino da Matemática. Autores como Zacarias e Moro (2005), Rysdyk (2010), Fernandes (2015), Arnoud (2016) e Murbach (2016) já

\footnotetext{
${ }^{3}$ Base Nacional Comum Curricular, homologada em março de 2018.

Tangram - Revista de Educação Matemática, Dourados - MS - v.3 n.1, pp. 02-17 (2020)
} 


\section{Alfabetização Matemática entrelaçada à Literatura Infantil: um estudo da percepção de professores alfabetizadores}

publicaram diferentes trabalhos voltados para essa temática, nos quais consideram a relevância da conexão entre Literatura Infantil e a Matemática. Assim, práticas que utilizam Histórias Infantis para introduzir, abordar e construir noções e conceitos matemáticos no Ciclo de Alfabetização constitui uma alternativa interessante de aproximação entre linguagem materna e a linguagem da Matemática formal, desenvolvendo nos estudantes habilidades de ler textos literários que abordam ideias matemáticas.

É importante salientar, também, que o trabalho com a Literatura Infantil no Ciclo de Alfabetização propicia ao aluno a sua imersão a um mundo imaginário, tão próprio dessa faixa etária (Jelinek, 2015), por meio de diferentes contextos literários. Logo, a utilização das histórias infantis nas aulas, proporciona um ensino contextualizado, lúdico e prazeroso, adquirindo significativa importância na formação de um aluno leitor por meio da imaginação e respectivamente da criação. Além disso, conforme os estudos de Dias (2019), trabalhar com histórias infantis já faz parte das práticas pedagógicas dos professores que atuam nos anos iniciais do Ensino Fundamental.

Nos últimos anos o Ministério da Educação enviou para as escolas públicas por meio do $\mathrm{PNBE}^{4}$ e do PNLD diversos acervos de livros de histórias infantis para serem utilizados nas salas de aula das turmas do Ciclo de Alfabetização. Ao ler essas histórias observa-se que elas trazem textos literários que se relacionam com as diferentes áreas do ensino, inclusive com a Matemática. Assim, muitos desses livros permitem introduzir ou explorar conceitos matemáticos que necessitam ser construídos ainda nos primeiros anos de escolaridade. Entretanto verifica-se que muitas vezes esses acervos ficam guardados nas escolas sem serem explorados ou utilizados pelos estudantes e professores, ou ainda, nas vezes em que os professores utilizam tais obras nas suas aulas, observa-se que essa prática ocorre de modo superficial, sem aproveitar as possibilidades que os livros oferecem para explorar noções e conceitos de diferentes áreas do conhecimento.

Diante disso, passamos a nos questionar se os professores que atuam no Ciclo de Alfabetização consideram possível utilizar as histórias infantis enviadas pelos programas do MEC para introduzir ou construir conceitos matemáticos. A partir desse questionamento estruturou-se este estudo, que faz parte de uma pesquisa mais ampla, intitulada

\footnotetext{
${ }^{4}$ Trata-se do "Programa Nacional Biblioteca na Escola" do Ministério da Educação. Esse programa tem como objetivo fomentar o acesso à cultura e à leitura nos alunos e professores das escolas públicas através da distribuição de acervos de obras literárias, de pesquisa e de referência.
}

Tangram - Revista de Educação Matemática, Dourados - MS - v.3 n.1, pp. 02-17 (2020) 


\section{Alfabetização Matemática entrelaçada à Literatura Infantil: um estudo da percepção de professores alfabetizadores}

“Alfabetização Matemática e Literatura Infantil: possibilidades de integração no Ciclo de Alfabetização". Assim, desenvolveu-se este recorde que teve por objetivo verificar se os professores alfabetizadores consideram possível a utilização de algumas histórias infantis que compõem os acervos do PNBE e do PNLD para introduzir ou construir noções e conceitos matemáticos; e caso afirmassem que sim, como eles desenvolviam tais práticas.

\section{Pensando a Alfabetização Matemática entrelaçada à Literatura Infantil}

Sabe-se que nos anos iniciais do Ensino Fundamental, sobretudo no Ciclo de Alfabetização, são desenvolvidos, nas diversas áreas do conhecimento, as noções e os conceitos que são relevantes para que o aluno prossiga com sucesso os seus estudos nos demais níveis do ensino. Entende-se que esse período se refere aos três primeiros anos do Ensino Fundamental, cujo público-alvo são os alunos com faixa etária entre 6 e 8 anos de idade, não havendo permanência dos mesmos no primeiro e no segundo anos desse período.

De acordo com os documentos do Pacto Nacional pela Alfabetização na Idade Certa (Brasil; 2012, 2014), o Ciclo de Alfabetização considera importantes os seguintes aspectos: o tempo de assimilação da cultura escolar pela criança, a apropriação da alfabetização linguística e a obtenção de "mais autoconfiança das crianças na aprendizagem dos demais componentes, sem que haja a reprovação nesse início de escolarização" (Brasil, 2012, p.23).

Nessa etapa o ensino da Matemática é voltado para a Alfabetização Matemática, que ainda segundo o Caderno de Apresentação do Pacto Nacional pela Alfabetização na Idade Certa (Brasil, 2014), diz respeito às práticas que levam em consideração as relações com o espaço e as formas, os processos de mediação, as estratégias de reunião, organização e verificação de atributos, a comparação, a classificação e a ordenação, além do uso e do registro das medidas. Nessa perspectiva, é importante que esses procedimentos estejam vinculados às situações significativas para os educandos. Portanto, a Alfabetização Matemática compreende uma leitura de mundo pela criança, superando o aspecto da decodificação dos números e a domínio das quatro operações.

Observa-se, entretanto, que o ensino da Matemática nessa etapa é voltado para a unidade temática dos Números, desconsiderando os demais campos do conhecimento matemático propostos pela BNCC, quais sejam: Álgebra, Geometria, Grandezas e Medidas e Probabilidade e Estatística. Nacarato, Mengali e Passos (2014), salientam que:

Tangram - Revista de Educação Matemática, Dourados - MS - v.3 n.1, pp. $02-17$ (2020) 


\section{Alfabetização Matemática entrelaçada à Literatura Infantil: um estudo da percepção de professores alfabetizadores}

Os relatórios de exames externos (PISA, ENEM, SAEB) sobre as competências matemáticas, divulgados recentemente, evidenciam que as competências de cálculo não bastam, pois não atendem às exigências da sociedade contemporânea. O mundo está cada vez mais matematizado, e o grande desafio que se coloca à escola e aos seus professores é construir um currículo de matemática que transcenda o ensino de algoritmos e cálculos mecanizados, principalmente nas séries iniciais, onde está a base da alfabetização matemática (Nacarato, Mengali E Passos, 2014, p. 32).

Além disso, há no Ciclo de Alfabetização uma preocupação com a Alfabetização Linguística, sendo reservado um período limitado para a Alfabetização Matemática. Como resultado desse fato há um baixo rendimento matemático dos alunos nos anos finais do Ensino Fundamental e no decorrer do Ensino Médio. Sobre isso Dorneles, Lima e Nogues (2017) enfatizam que é complexo apresentar os desafios encontrados pelos professores alfabetizadores no que se refere à construção de conceitos matemáticos, pois além de os mesmos possuírem a responsabilidade de desenvolver a Alfabetização Linguística, deixando a Alfabetização Matemática em segundo plano, há ainda a percepção do imaginário social de que a Matemática é um componente curricular complicado tanto para se aprender quanto para se ensinar.

Tais questões trazem sérias consequências, dentre elas podemos citar o desempenho dos alunos em Matemática é mais baixo do que em Língua Portuguesa, o aumento do desinteresse deles no que diz respeito aos conceitos desenvolvidos nesse componente curricular. Outro fator é o desencantamento dos estudantes pela Matemática, tida por eles como "difícil de ser compreendida".

Dessa maneira, é interessante que o professor que atua nos primeiros anos da escolarização diversifique as estratégias de ensino para que o aluno amplie suas estratégias de aprendizagem na construção dos conceitos matemáticos, contemplando os diversos campos da Alfabetização Matemática. Meirieu (1998) ressalta que:

[...] uma estratégia de aprendizagem se constitui de maneira complexa e faz com que intervenham variáveis de ordem muito diferentes. E, desde já, impõe-se uma conclusão: a prática didática deverá esforçar-se para fazer com que variem as estratégias de ensino para que os sujeitos possam utilizar sua estratégia de aprendizagem (Meirieu, 1998, p. 138).

Assim sendo, uma estratégia de ensino que poderá contribuir para a construção dos conceitos matemáticos no Ciclo de Alfabetização acreditamos estar no possível 


\section{Alfabetização Matemática entrelaçada à Literatura Infantil: um estudo da percepção de professores alfabetizadores}

entrelaçamento da Literatura Infantil à Alfabetização Matemática. Smole (1998) afirma que estabelecer ligações matemáticas propicia ao educando relacionar as ideias matemáticas à realidade de modo a deixar específica sua participação e utilização nos diversos campos da atuação humana, destacando, assim, o uso cultural e social da matemática.

Compreende-se, portanto, que entrelaçar a Alfabetização Matemática à Literatura Infantil propicia aos alunos do Ciclo de Alfabetização o entendimento do que estão estudando, aproximando-os da linguagem matemática contida nas histórias infantis. Essa abordagem oportuniza o estabelecimento de relações cognitivas entre linguagem materna e a linguagem da matemática formal, desenvolvendo habilidades e construindo conceitos matemáticos.

Para Vygotsky (1984), a criança busca a satisfação das suas necessidades por meio do imaginário. Logo, a literatura infantil no Ciclo de Alfabetização pode possibilitar aos educandos a sua imersão no mundo imaginário, contribuindo para o seu desenvolvimento nas diversas áreas do conhecimento, inclusive na Alfabetização Matemática. Para Vygotsky (1984):

Palavras e gestos possibilitam transformar uma coisa em outra. É a linguagem que torna possível o faz de conta, a criação da situação imaginária. A criação não emerge do nada, mas requer um trabalho de construção histórica e participação da criança na cultura. A brincadeira infantil é, assim, um lugar por excelência de incorporação de práticas e exercícios de papéis sociais (Vygotsky, 1984, p. 110).

Percebe-se que a linguagem é relevante para o estímulo da imaginação e da criatividade na criança. Portanto, a literatura infantil promove por meio da linguagem situações de interação que são necessárias para a construção de diversos conceitos pela criança, incluindo conceitos matemáticos. Logo, a exploração de conceitos matemáticos por meio de histórias infantis permite aos alunos além de uma aprendizagem significativa desses conceitos, o desenvolvimento de habilidades tanto matemáticas quanto linguísticas. De acordo com Lopes (2009),

A leitura de textos que tenham como objetos conceitos e procedimentos matemáticos, história da matemática ou reflexões sobre a matemática, seus problemas, seus métodos, seus desafios pode, porém, muito mais do que orientar a execução de determinada técnica, agregar elementos que não só favoreçam a constituição de significados dos conteúdos matemáticos, mas também colaborarem para a produção de sentidos da própria matemática e de sua aprendizagem pelo aluno (Lopes, 2009, p.26).

Tangram - Revista de Educação Matemática, Dourados - MS - v.3 n.1, pp. 02-17 (2020) 


\title{
Alfabetização Matemática entrelaçada à Literatura Infantil: um estudo da percepção de professores alfabetizadores
}

Por fim, os conceitos matemáticos contidos nas histórias infantis propiciam ao educando além de um embasamento para a construção de conhecimentos matemáticos posteriores, a exploração de acontecimentos e lugares e o estabelecimento de relações, bem como a solução dos desafios propostos pelos personagens das histórias. Entretanto, para que isso ocorra é conveniente verificar o aspecto formativo da Literatura Infantil, observando a sua riqueza de linguagens e os aspectos lúdicos contemplados.

\section{Metodologia}

Para a realização desse estudo, foi realizada uma pesquisa predominantemente qualitativa, uma vez que o mesmo é voltado para a análise de questões abertas propostas em um questionário. Ao descrever uma pesquisa qualitativa, Moreira (2011) destaca que:

\begin{abstract}
$\mathrm{O}$ interesse central dessa pesquisa está na interpretação dos significados atribuídos pelos sujeitos à suas ações em uma realidade socialmente construída, através de observação participativa, isto é, o pesquisador fica imerso o fenômeno de interesse. Os dados obtidos por meio dessa participação ativa são de natureza qualitativa e analisados de forma correspondente. As hipóteses são geradas durante o processo investigativo. $\mathrm{O}$ pesquisador busca universais concretos alcançados através do estudo profundo de casos particulares e da comparação desse caso com outros estudados também com grande profundidade. Através de uma narrativa detalhada, o pesquisador busca credibilidade para seus modelos interpretativos. (Moreira, 2011, p. 76, grifos do autor).
\end{abstract}

Contudo, essa pesquisa também apresenta aspectos quantitativos, uma vez que as questões fechadas do questionário proposto foram analisadas quantitativamente.

Entendemos o questionário da mesma forma que Gil (2010), como uma eficaz técnica de interrogação, constituído por um conjunto de questões, que serão respondidas por escrito pelo sujeito pesquisado. O emprego do questionário nesse trabalho, visou conhecer o perfil de alguns professores alfabetizadores que atuam na rede pública de ensino (municipal e estadual) da região estudada, bem como verificar quais são as suas ideias acerca da Alfabetização Matemática integrada à Literatura Infantil. Esse questionário foi estruturado através de questões abertas e fechadas, cujas respostas produziram subsídios indispensáveis para a organização e delineamento da pesquisa.

Tangram - Revista de Educação Matemática, Dourados - MS - v.3 n.1, pp. 02-17 (2020) 


\section{Alfabetização Matemática entrelaçada à Literatura Infantil: um estudo da percepção de professores alfabetizadores}

Dentre os diferentes aspectos que desejava-se compreender, estruturou-se o questionário apresentado no Quadro 1.

Quadro 1: Questionário

1. Qual a sua idade?
( ) Menos de 20 anos
( ) 20 a 25 anos
( ) 26 a 35 anos
( ) 36 a 45 anos
( ) 46 a 50 anos
( ) 51 a 55 anos
( ) Mais de 55 anos

2. Tempo de atuação como professora no Ciclo de Alfabetização:
( ) Menos de 5 anos
( ) 5 a 10 anos
( ) 11 a 15 anos
( )16 a 20 anos
( ) 21 a 25 anos
( ) 26 a 30 anos
( ) Mais de 30 anos

3. Qual é a sua formação? ( ) Magistério ( ) Graduação em:

4. Possui Pós-Graduação? ( ) Sim ( ) Não

5. Se sim, qual?

6. Você considera que a Alfabetização Matemática possui a mesma relevância da Alfabetização Linguística no Ciclo de Alfabetização? ( ) Sim ( ) Não. Por quê?

7. Quais os conteúdos que você considera indispensáveis para Alfabetização Matemática?

8. Você tem conhecimento sobre quais são as Unidades Temáticas da Matemática propostas pela Base Nacional Comum Curricular? ( ) Sim ( ) Não

9. Você tem conhecimento e acesso às obras de Literatura Infantil que são enviadas para as escolas pelo Ministério da Educação por meio do PNLD e outros programas? ( ) Sim ( ) Não

10. Se sim, como você costuma utilizá-las?

11. Você considera possível utilizar histórias infantis para introduzir, abordar ou explorar conceitos matemáticos no Ciclo de Alfabetização? ( ) Sim ( ) Não

12. Você já trabalhou dessa forma? ( ) Sim ( ) Não

13. Se sim, como foi essa prática?

Fonte: As autoras

Para a realização desse questionário, visitou-se um total de 3 escolas, de dois municípios diferentes, que foram denominados como municípios A e B. Dessas 3 escolas, uma pertence à rede municipal do Município A. Esse município faz parte da Microrregião e Mesorregião de Porto Alegre (RS), situando-se ao norte dessa Capital. Possuindo 255.762 habitantes, o município A conta com setenta e seis escolas da rede municipal e vinte e cinco da rede estadual. Visitou-se, ainda, uma escola da rede municipal do Município B. Esse Tangram - Revista de Educação Matemática, Dourados - MS - v.3 n.1, pp. 02-17 (2020) 


\section{Alfabetização Matemática entrelaçada à Literatura Infantil: um estudo da percepção de professores alfabetizadores}

Município é vizinho do Município A, pertencendo à Mesorregião Metropolitana de Porto Alegre. Possui 6.885 habitantes e um 19 total de 4 escolas municipais e 2 de escolas estaduais. Também nesse Município B visitou-se uma das escolas da rede estadual. Conversou-se com as professoras que atuam no Ciclo de Alfabetização dessas respectivas escolas, esclarecendo sobre a importância desse instrumento para o fornecimento de informações para essa pesquisa. Entregou-se as questões impressas combinando um dia posterior para a sua entrega.

Foram distribuídos um total de 21 questionários. Desses, 9 foram entregues para professoras da escola municipal situada no Município A, 8 para professoras da escola municipal situada no município B e 4 para professoras da escola estadual. Porém, quando se voltou na escola do Município A para reunir os questionários já respondidos, apenas 5 professoras o entregaram. Na escola municipal situada no Município B, 6 professoras devolveram o questionário respondido, e na escola estadual todas as professoras retornaram o mesmo. Houveram outras tentativas de buscar nas escolas municipais dos questionários que não foram entregues no período combinado, entretanto o restante das professoras não o devolveu. Logo, dispôs-se de um total de 15 questionários para serem analisados.

\section{Buscando compreender a percepção dos professores}

A tabela abaixo mostra as respostas das professoras alfabetizadoras ${ }^{5}$ para as questões fechadas que foram propostas no questionário. Foram analisados um total de quinze questionários. As professoras foram identificadas como P1, para a primeira professora, até P15, para a última.

Tabela 1: Respostas às questões fechadas. ${ }^{6}$

\footnotetext{
${ }^{5}$ Considerando que os questionários foram respondidos unanimemente por professoras, a partir dessa seção não iremos mais nos referir a tais sujeitos na forma genérica "professores", mas sim, como "professoras".

${ }^{6}$ Buscando facilitar a compreensão da Tabela 1, dispõe-se a seguir as questões fechadas do questionário proposto.

Questão 6: Você considera que a Alfabetização Matemática possui a mesma relevância da Alfabetização Linguística no Ciclo de Alfabetização?

Questão 8: Você tem conhecimento sobre quais são as Unidades Temáticas da Matemática propostas pela BNCC?
}

Tangram - Revista de Educação Matemática, Dourados - MS - v.3 n.1, pp. 02-17 (2020) 
Alfabetização Matemática entrelaçada à Literatura Infantil: um estudo da percepção de professores alfabetizadores

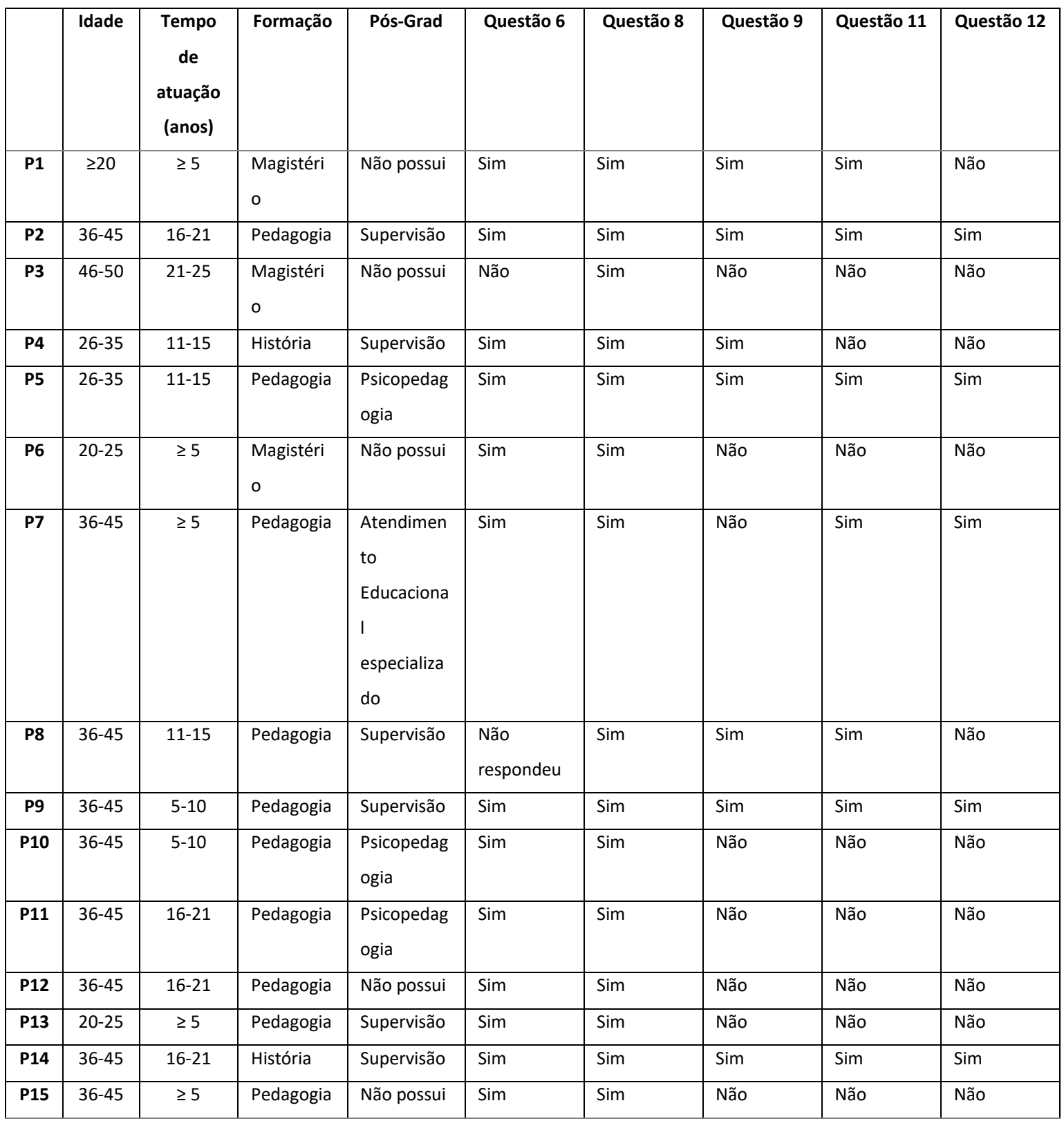

Fonte: As autoras

Questão 9: Você tem conhecimento e acesso às obras de Literatura Infantil enviadas para as escolas pelo Ministério da Educação por meio do PNLD e outros programas?

Questão 11: Você considera possível utilizar histórias infantis para introduzir, abordar ou explorar conceitos matemáticos no Ciclo de Alfabetização?

Questão 12: Você já trabalhou dessa forma?

Tangram - Revista de Educação Matemática, Dourados - MS - v.3 n.1, pp. $02-17$ (2020) 


\section{Alfabetização Matemática entrelaçada à Literatura Infantil: um estudo da percepção de professores alfabetizadores}

Ao observar essa tabela, percebe-se que a maioria das professoras possuem entre 36 e 45 anos de idade, e os períodos em que atuam como professoras alfabetizadoras são variados, sendo que a maioria delas atua no Ciclo de Alfabetização há mais de cinco anos, o que demonstra o vínculo que as mesmas possuem com essa etapa do ensino. Entretanto apenas uma professora atua há mais de vinte e um anos como alfabetizadora. Verifica-se que essa professora P3 não possui formação acadêmica. As demais professoras cuja formação é o Magistério estão cursando a graduação, mas não a concluíram.

Além disso, a maioria das professoras são graduadas em Pedagogia. Das dez professoras que possuem pós-graduação, a maioria é na área da Supervisão Escolar. Observa-se que mesmo sendo alfabetizadoras, nenhuma dessas professoras é pós-graduada em alfabetização e letramento, ou ainda, em alguma área específica voltada ao ensino.

Quanto à relevância da Alfabetização Matemática, proposta na questão 6, a maioria das professoras considera que a mesma tem importância igual à da Alfabetização Linguística. Apenas uma professora P3, responde que a relevância não é a mesma entre as duas áreas:

Acho que as duas são importantes. Mas primeiro tem que ensinar a ler e escrever. Depois disto, os outros conteúdos os alunos aprendem bem rápido. (P3)

Nessa resposta percebe-se que a professora elege a Alfabetização Linguística como pré-requisito para a aprendizagem dos conteúdos das demais áreas do conhecimento, inclusive para a Alfabetização Matemática. Sobre isso, Dorneles, Lima e Nogues (2017) ressaltam que:

\footnotetext{
A tarefa de descrever os conceitos iniciais da matemática e os desafios enfrentados pelos professores de séries iniciais é complexa por, pelo menos, duas razões. A primeira diz respeito ao fato de que tais professores têm uma tarefa gigantesca: alfabetizar todos os alunos, tarefa que, muitas vezes, deixa a aprendizagem da matemática em segundo plano. Á matemática é dado um tempo menor na Escola, uma importância relativa na hora de aprovar ou reprovar, especialmente nas séries iniciais, uma condição de disciplina de segunda categoria em relação à língua portuguesa. (Dorneles; Lima; Nogues, 2017, p. 139).
}

A professora $\mathrm{P} 10$, ressalta que:

As duas áreas apresentam a mesma relevância porque estão interligadas, inclusive no dia-a-dia, dentro e fora do ambiente escolar.

Tangram - Revista de Educação Matemática, Dourados - MS - v.3 n.1, pp. 02-17 (2020) 


\section{Alfabetização Matemática entrelaçada à Literatura Infantil: um estudo da percepção de professores alfabetizadores}

Essa resposta evidencia a importância que a professora atribui em desenvolver tanto a Alfabetização Matemática quanto a Alfabetização Linguística.

$\mathrm{Na}$ questão 7, solicitou-se que as professoras alfabetizadoras elencassem os conteúdos que consideram indispensáveis para a Alfabetização Matemática. Das quinze professoras, três não responderam essa questão. Das demais, destacam-se as seguintes respostas:

Considero importantes todos os conteúdos que precisam ser trabalhados. Por exemplo: numerais e quantidades até 9, ordem crescente e decrescente dos números, operações simples de adição e de subtração e a dezena. (P2)

Eu sempre trabalho muito as quatro operações básicas e o sistema de numeração decimal. Eles precisam ter bem construídos esses conteúdos, pois todo o restante da matemática parte desses conteúdos. (P5)

Conhecer e identificar os números, recitação numérica, adição e subtração. (P6)

Seriação, classificação, numeral, sistema monetário, geometria, operações matemáticas e sistema decimal. (P9)

As quatro operações, unidade, dezena, numeral (escrita, quantidade, tempo cronológico), histórias matemáticas. (P12)

Ao observar essas respostas, percebe-se que as professoras consideram indispensáveis os conteúdos da Unidade Temática dos Números. Em todas as respostas acima, apenas as professoras P9 e P12, mencionaram conteúdo das outras Unidades Temáticas da Matemática. Sobre isso, Maia e Maranhão (2017) enfatizam que:

[...] ao se pensar o que considerar como alfabetização e o letramento matemático, é comum, em nossa prática, percebermos a tendência dos educadores dos anos iniciais em sala de aula, reduzir o trabalho ao campo numérico ou a uma parte relacionada a ele. (Maia; Maranhão, 2017, p. 26).

Quanto ao conhecimento sobre as Unidades Temáticas da Base Nacional Comum Curricular, proposta na questão 8, todas as professoras responderam que conhecem as mesmas. Acredita-se que isso aconteça devido às formações que recentemente ocorreram nas escolas acerca desse tema. Entretanto, percebe-se uma contradição com as respostas da questão 7, pois como visto anteriormente, as professoras destacaram os conteúdos da Unidade Temática dos Números como de maior relevância para a Alfabetização Matemática.

Tangram - Revista de Educação Matemática, Dourados - MS - v.3 n.1, pp. 02-17 (2020) 


\section{Alfabetização Matemática entrelaçada à Literatura Infantil: um estudo da percepção de professores alfabetizadores}

Quando questionadas, na questão 9, acerca do conhecimento e acesso às obras de Literatura Infantil enviadas pelo Ministério da Educação por meio do PNLD e de outros programas, sete professoras responderam que têm conhecimento e acesso e oito professoras não têm. Percebe-se que a maioria das professoras que têm conhecimento e acesso à essas obras são pós-graduadas em supervisão escolar. Possivelmente, essa condição propicia o conhecimento acerca dos programas do Ministério da Educação que realizam a distribuição dos acervos de livros de Literatura Infantil. Em seguida, quando questionadas, na questão 10, sobre como utilizam essas obras em suas aulas, seis das alfabetizadoras que têm conhecimento e acesso às mesmas responderam que como hora do conto e uma respondeu que como sequência didática.

Na questão 11, quando indagadas sobre a possibilidade de integrar Alfabetização Matemática e Literatura Infantil, sete professoras responderam que consideram possível essa integração, entretanto, oito responderam que não. Na questão 12, dessas sete professoras, cinco responderam que já realizaram práticas envolvendo Matemática e Literatura Infantil. Quando questionadas na questão 13 sobre de que maneira se deu tal prática, a maioria respondeu que foi por meio de uma sequência didática.

Foi uma experiência muito boa, que eu apresentei no final do pacto. Uma sequência didática que eu realizei com os meus alunos através da história "chá das dez”. Vou levar para sempre na minha memória. (P2)

Trabalhei com uma história da caixa do pacto para fazer uma sequência didática, explorando as figuras geométricas, tamanhos e medidas. (P5)

Através da história "o grande rabanete”, trabalhei ordem crescente e decrescente.

Foi por meio de uma sequência didática com o livro cuidado com o lobo. Fiz com os alunos a exploração dos números, das medidas para apresentar no pacto. Muito produtivo. (P9)

Uma sequência didática com a história "Camilão, o Comilão”. Em uma das atividades, os alunos representavam a quantidade e utilizavam, no decorrer da história, uma cesta de frutas para fazer a contagem. (P14)

Ainda referente a essa questão, percebe-se nas respostas acima que as professoras que articularam práticas de integração entre Matemática e Literatura Infantil por meio de sequência didática, foram as que participaram das formações do Pacto Nacional pela Tangram - Revista de Educação Matemática, Dourados - MS - v.3 n.1, pp. 02-17 (2020) 


\section{Alfabetização Matemática entrelaçada à Literatura Infantil: um estudo da percepção de professores alfabetizadores}

Alfabetização na Idade Certa (PNAIC). Sobre isso, Piccoli, Corso, Andrade e Sperrhake (2017) reforçam que o PNAIC foi:

[...] um programa que integra uma política de formação de professores alfabetizadores de uma magnitude e alcance únicos na história da formação continuada brasileira. Os resultados favoráveis do PNAIC já são visíveis em pesquisas acadêmicas, publicação de divulgação de professores, mas, sobretudo, na progressão das aprendizagens que acompanhamos cotidianamente nas salas de aula das escolas públicas. (Piccoli; Cors; Andrade; Sperrhake, 2017, p. 14).

\section{Considerações finais}

Diante de tal estudo foi possível perceber que a maioria das professoras alfabetizadoras que participaram da pesquisa desconhecem as obras enviadas pelo Ministério da Educação para as escolas por meio do PNLD e de outros programas. Isso reforça a ideia de que esses acervos têm sido subutilizados nas escolas. Acredita-se que isso aconteça devido ao fato de que, mesmo que sejam destinados para serem utilizados em sala de aula, esses livros ficam em outros espaços das escolas, como nas bibliotecas ou salas de coordenação, dificultando o acesso dos professores aos mesmos.

Além disso, a maior parte das professoras não integram a Alfabetização Matemática com a Literatura Infantil em práticas que tenham a finalidade de explorar, introduzir ou construir noções e conceitos matemáticos, pois não consideram que essa seja uma experiência possível de ser desenvolvida, respondendo assim, a questão que originou essa pesquisa. Observa-se a dificuldade em variar as estratégias de ensino, ou, ainda, o desconhecimento por parte do professor sobre quais são as noções ou conceitos matemáticos que necessitam ser construídos no Ciclo de Alfabetização.

Verificou-se mais uma vez através desse estudo que os professores alfabetizadores enfatizam a Unidade Temática dos Números, deixando a um segundo plano os conceitos matemáticos das demais Unidades Temáticas da Matemática. Confirma-se assim, o fato de que nos primeiros anos de escolaridade há uma preocupação maior com a alfabetização linguística, já que destacar os objetos do conhecimento e as habilidades referentes aos Números mostra a necessidade, por parte dos professores, de abordar apenas o que seria o "essencial" a essa etapa, deixando um maior período reservado para as questões da linguagem.

Tangram - Revista de Educação Matemática, Dourados - MS - v.3 n.1, pp. 02-17 (2020) 


\section{Alfabetização Matemática entrelaçada à Literatura Infantil: um estudo da percepção de professores alfabetizadores}

Neste mesmo sentido, a preocupação excessiva com a Unidade Temática dos Números deixa diversas lacunas no conhecimento matemático do estudante no decorrer da sua vida escolar. Como consequência, nos anos finais do Ensino Fundamental, em que a Matemática adquire a mesma importância da linguagem, percebe-se que os estudantes ainda não construíram as noções e os saberes necessários para a compreensão de conceitos mais elaborados, resultando no desencantamento, na frustração e no fracasso em Matemática.

\section{Referências}

Arnoud, Denise Soares. (2016). A Matemática presente em livros de leitura: possibilidades para a educação infantil. Disponível em https://lume.ufrgs.br/handle/10183/148194. Acesso em: 13 de out. de 2018.

Brasil. Ministério da Educação. (2012). Manual do PNAIC. Disponível em: http://pacto.mec.gov.br/images/pdf/pacto_livreto.pdf. Acesso em: 25 de out. de 2018.

Brasil. Secretaria de Educação Básica. (2014). Pacto Nacional pela Alfabetização na Idade Certa: apresentação. Brasília: MEC, SEB.

Dias, Rosimeri da Silva. (2019). Formação continuada de professores que ensinam matemática nos anos iniciais: espaço de (re)construção de saberes. 2019. $75 f$. Dissertação (Mestrado em Ensino de Ciências Exatas) - Universidade Federal do Rio Grande.

Dorneles, Beatriz Vargas; Lima, Elielson Magalhães e Nogues, Camila Peres. (2017). Aprendizagem da Matemática nos anos iniciais: conceitos e desafios. In: Piccoli, L., Corso, L., Andrade, S., Sperrhake, R. (Orgs.). PNAIC UFRGS: práticas de alfabetização, aprendizagem da matemática e políticas públicas. São Leopoldo: Editora Oikos. 139 - 158.

Fernandes, Michelli de Souza Novikoff de Oliveira. (2015). Literatura Infantil nas aulas de Matemática: uma estratégia facilitadora para o processo de aprendizagem. 2015. 38f. Monografia (Pedagogia) - FUNVIC-SP. Disponível em: http://www.bibliotecadigital.funvicpinda.org.br:8080/jspui/handle/123456789/309.

Acesso em 13 de out. de 2018.

Gil, Antonio Carlos. (2010). Como elaborar projetos de pesquisa. 5. ed. São Paulo: Atlas.

Jelinek, Karin Ritter. (2015). Jogos nas aulas de Matemática: brincadeira ou aprendizagem? Saarbrücken: Novas Edições Acadêmicas.

Lopes, Celi Aparecida Espasandin. (2009). Escritas e leituras na educação matemática. Belo Horizonte: Autêntica.

Tangram - Revista de Educação Matemática, Dourados - MS - v.3 n.1, pp. 02-17 (2020) 


\section{Alfabetização Matemática entrelaçada à Literatura Infantil: um estudo da percepção de professores alfabetizadores}

Maia, Madeline Gurgel Barreto; Maranhão, Cristina. (2017). A alfabetização matemática na sala de aula: uma ideia a partir da ampliação do ensino fundamental (de 9 anos). In: MAIA, Madeline Gurgel Barreto Maia; BRIÃO, Gabriela Félix Org(s). Alfabetização matemática: tendências atuais. Curitiba: CRV.

Meirieu, Philippe. (1998). Aprender... sim, mas como? Porto Alegre: Artmed.

Moreira, Marco Antônio. (2011). Metodologias de Pesquisa em Ensino. São Paulo: Editora da Física.

Murbach, Marcia Costa Graichen. (2017). Histórias infantis e Alfabetização Matemática. 2017. 236f. Dissertação (Mestrado em Educação) - Programa de Pós-Graduação em Educação em Ciências e em Matemática da Universidade Federal do Paraná. Disponível em: http://acervodigital.ufpr.br/bitstream/handle/1884/49568/R\%20\%20D\%20\%20MARCIA\%20COSTA\%20GRAICHEN\%20MURBACH\%20.pdf?se quence $=1 \&$ is Allowed $=\mathrm{y}$. Acesso em 18 de fev. de 2018.

Nacarato, Adair Mendes; Mengali, Brenda Leme da Silva; Passos, Cármen Lúcia Brancaglion. (2014). A matemática nos anos iniciais do ensino fundamental: Tecendo fios do ensinar e do aprender. $2^{\mathrm{a}}$ edição. Belo Horizonte: Editora Autêntica.

Piccoli, Luciana; Corso, Luciana Vellinho; Andrade, Sandra dos Santos; Sperrhake, Renata. (2017). Apresentação. In: Piccoli, L., Corso, L., Andrade, S., Sperrhake, R. (Orgs.). PNAIC UFRGS: práticas de alfabetização, aprendizagem da matemática e políticas públicas. São Leopoldo: Editora Oikos. 13 - 18.

Rysdyk, Marcia Regina de Azeredo. A Matemática do Era uma vez. (2010). Monografia (Pedagogia) - UFRGS. 2010. 66f. Disponível em: http://www.lume. ufrgs.br/bitstream/handle/10183/36717/000818224. pdf?sequence=1. Acesso em 18 de fev. de 2018.

Smole, Kátia Cristina Stocco. (Org.). (1998). Era uma vez na Matemática: uma conexão coma literatura infantil. São Paulo: IME/USP.

Vygotsky, Lev S. (1984). A formação social da mente. São Paulo: Editora Martins Fontes.

Zacarias, Eloísa; Moro, Maria L. F. (2005). A matemática das crianças pequenas e a literatura infantil. Educar, $C$

Recebido: $13 / 02 / 2020$

Aprovado:28/03/2020

Tangram - Revista de Educação Matemática, Dourados - MS - v.3 n.1, pp. $02-17$ (2020) 